\title{
Effectiveness of shared pharmaceutical care for older patients: RESPECT trial findings
}

RESPECT trial team

\section{ABSTRACT}

\section{Background}

The pharmaceutical care approach serves as a model for medication review, involving collaboration between GPs, pharmacists, patients, and carers. Its use is advocated with older patients who are typically prescribed several drugs. However, it has yet to be thoroughly evaluated.

Aim

To estimate the effectiveness of pharmaceutical care for older people, shared between GPs and community pharmacists in the UK, relative to usual care.

\section{Design of study}

Multiple interrupted time-series design in five primary care trusts which implemented pharmaceutical care at 2 month intervals in random order. Patients acted as their own controls, and were followed over 3 years including their 12 months' participation in pharmaceutical care.

\section{Setting}

In 2002, 760 patients, aged $\geq 75$ years, were recruited from 24 general practices in East and North Yorkshire. Sixty-two community pharmacies also took part. A total of 551 participants completed the study.

\section{Method}

Pharmaceutical care was undertaken by community pharmacists who interviewed patients, developed and implemented pharmaceutical care plans together with patients' GPs, and thereafter undertook monthly medication reviews. Pharmacists and GPs attended training before the intervention. Outcome measures were the UK Medication Appropriateness Index, the Short Form-36 Health Survey (SF-36), and serious adverse events.

Results

The intervention did not lead to any statistically significant change in the appropriateness of prescribing or health outcomes. Although the mental component of the SF-36 decreased as study participants become older, this trend was not affected by pharmaceutical care.

\section{Conclusion}

The RESPECT model of pharmaceutical care

(Randomised Evaluation of Shared Prescribing for Elderly people in the Community over Time) shared between community pharmacists and GPs did not significantly change the appropriateness of prescribing or quality of life in older patients.

\section{Keywords}

health services for the aged; medication therapy management; pharmaceutical care; polypharmacy; randomised controlled trial.

\section{INTRODUCTION}

The UK is facing unprecedented growth in the number of older people. ${ }^{1}$ These people are vulnerable to adverse effects of multiple drug use through physiological change, poor adherence to prescribed drugs, and interactions between these drugs. ${ }^{2,3}$ Thus there is great potential for drugs to cause morbidity and hospital admission, especially as three-quarters of prescriptions for older people in the UK are repeat prescriptions, ${ }^{4}$ and doctors review only few of these regularly. Hence the National Service Framework for Older People ${ }^{1}$ specifies regular review of medication prescribed to older people.

$S$ Richmond, MSc, research fellow; V Morton, $M S c$, research fellow; B Cross, BSc, research associate, Department of Health Sciences, University of York. I Chi Kei Wong, PhD, professor, School of Pharmacy, University of London; I Russell, DSc, professor, School of Medicine, Swansea University; Z Philips, $P h D$, honorary fellow, Centre for Health Economics, University of York, UK. J Miles, PhD, behavioural scientist, RAND Corporation, Santa Monica, California, US. A Hilton, PhD, lecturer, Faculty of Health and Social Care, The University of Hull; G Hill, BSc (Hons), professional development pharmacist, East Riding and Hull Local Pharmaceutical Committee, Hull; A Farrin, MSc, director and principal statistician (Health Sciences), Clinical Trials Research Unit, University of Leeds; S Coulton, MSc, professor, Centre for Health Service Studies, University of Kent; H Chrystyn, PhD, head of pharmacy, University of Huddersfield; P Campion, $P h D$, emeritus professor of primary care medicine, Postgraduate Medical Institute, The University of Hull, UK.

Address for correspondence

Stewart Richmond, Department of Health Sciences, University of York, Heslington, York, UK, YO10 5DD. E-mail: sjr503@york.ac.uk

Submitted: 9 January 2009; Editor's response: 20 March 2009; final acceptance: 18 May 2009.

(C)British Journal of General Practice

This is a full-length article of an abridged version published in print and originally published online first on $4 \mathrm{Dec} 2009$. Cite this version as: Br J Gen Pract 2009; DOI: 10.3399/bjgp09X473295 (abridged text, in print: Br J Gen Pract 2010; 59: 14-20). 
Pharmaceutical care, which originated in the US, leaves doctors ultimately responsible for patients' care, but gives pharmacists the role of moderating drug management in collaboration with doctor, patient, and carer. ${ }^{5}$ Both the Royal Pharmaceutical Society of Great Britain and the UK Clinical Pharmacy Association recommend pharmaceutical care as the method of medication review for older people in the UK. ${ }^{6,7}$

The central aim of pharmaceutical care is to ensure that medication is prescribed and used appropriately. This is achieved through a collaborative and iterative process of reviewing medication according to the dynamic status of a person's health. This relies on communication between the pharmacist, who typically initiates this process, the patient, and the GP. Problems relating to compliance and adverse drug interactions are likely to be highlighted by the review process. This may feed into the care plan and alter prescribing, together with methods of issuing medication. The process of conducting a review may also present a suitable opportunity to modify prescribing in favour of generic drugs. This has the potential to reduce the cost of drugs $^{8}$ and the incidence of adverse events, and thus improve patients' health-related quality of life. Although pharmaceutical care is advocated in the UK, it has yet to be thoroughly evaluated. ${ }^{9}$

The RESPECT trial (Randomised Evaluation of Shared Prescribing for Elderly people in the Community over Time) was designed to estimate the effect of pharmaceutical care on the appropriateness of prescribing; patients' knowledge, adherence, and quality of life; and the incidence of adverse events. The cost-effectiveness is estimated in the accompanying paper. ${ }^{10}$

\section{METHOD}

\section{Study design}

A randomised multiple interrupted time-series design was used (Appendix 1). ${ }^{9}$ Five primary care trusts (PCTs) - then named Eastern Hull, East Yorkshire, Selby \& York, West Hull, and Yorkshire Wolds \& Coast - implemented pharmaceutical care at 2month intervals from March 2003 until November 2003 in an order determined by blind randomisation of these 'clusters' at the trial coordinating centre. ${ }^{11}$ In this way, each PCT acted as a control for the other four. Within each PCT, participants, GPs, and pharmacists acted as their own controls. All were blind to the randomisation sequence until 3 months before the intervention began in their PCT, to allow sufficient time for training. Moreover, pharmacists and GPs were blind to the identity of participants until immediately before the intervention began. This design protects against many sources of bias,

\section{How this fits in}

Medication prescribed to older people often has iatrogenic effects on their health and generates many hospital admissions. Both the Royal Pharmaceutical Society of Great Britain and the UK Clinical Pharmacy Association recommend

pharmaceutical care as a method of reviewing this medication. This study found that pharmaceutical care provided by community pharmacists does not improve appropriateness of medication or quality of life, either mental or physical, or reduce serious adverse events. There is still a need to evaluate whether medication review within general practice can improve prescribing for older people.

including changes in health policy over time, contamination between adjacent practices and pharmacies, and the 'resentful demoralisation' of non-participants. ${ }^{12}$

\section{Interventions}

All recruited patients received pharmaceutical care adapted to British primary care. ${ }^{9}$ Training was provided over two sessions for all the participating pharmacists, involving their associated GP prescribers in the second session. Training covered the theory and practice of pharmaceutical care, practical exercises in collaborating with GPs, and involving patients and carers to construct, implement, and monitor a 'pharmaceutical care plan'. Training took place just before the start of each 12-month period of pharmaceutical care.

\section{Recruitment}

Recruitment started in May 2002 and finished in November 2002. All general practices in the five PCTs were invited to take part. ${ }^{9}$ From those who expressed interest, eight practices from Selby \& York (the largest PCT) and four practices from each of the four smaller PCTs were selected, all stratified by practice size. All community pharmacies with a permanent pharmacist and patients in common with sampled practices in the same PCT were also invited. For inclusion, participants needed to be $\geq 75$ years of age and taking at least five drugs on repeat prescription at the time of recruitment. Practice records were searched for patients meeting the inclusion criteria (Appendix 2 ), ${ }^{13}$ and these patients were invited to opt into the study. Potential participants were interviewed in their home or at their GP's surgery.

\section{Outcome measures}

The primary outcome was the UK Medication Appropriateness Index (UK-MAI) which the current authors anglicised from the US version. ${ }^{14-16}$ The resulting score depends on the number of drugs being prescribed and the appropriateness of each. As an individual drug can score between 0 
(completely appropriate) and 20 (completely inappropriate), the lower the score the better. Independent pharmacists (blind to the timing of the data, in particular whether prescribed before, during or after the intervention) were recruited to derive an UK-MAI score for each drug (and thus each patient, by summing over all his or her drugs) at each time point. These assessors were given patients' anonymised practice data for each of five such times, including a full summary of drugs, clinical problems, laboratory tests, and primary and secondary care received. Secondary outcomes included quality of life measured by the Short Form-36 Health Survey (SF-36), ${ }^{17}$ and health utility measured by the EQ-5D. ${ }^{18}$ Costs of pharmaceutical care and associated health care to the NHS were also collected. ${ }^{10}$

\section{Data collection}

Researchers collected data from participants using questionnaires completed by post, telephone interview, or home visit, depending on the characteristics of each responder. ${ }^{9}$ They did so on five occasions, two of which were the same for all five PCTs: recruitment and final time points. The other three time points reflected the progress of pharmaceutical care in each PCT: baseline, and 3
Figure 1. Progress of participants through the RESPECT trial. $P C T=$ primary care trust. and 12 months after pharmaceutical care began (Appendix 1). Questionnaires included the two generic measures (SF-36 and EQ-5D) and the cost of health care to participants. During home visits, researchers also collected data on participants' adherence using pill counts, and their knowledge of the drugs they had been prescribed.

Researchers collected 4 years' worth of data for the UK-MAI retrospectively from participants' general practices from April to September 2005. These data came only from practices using the Egton Medical Information Service (EMIS) because that system could download the required data electronically. Fortunately, 633 of the 760 patients recruited into the trial were registered with EMIS practices. Data from 577 patients were analysed, excluding those who withdrew consent or died before the intervention, but including those who died after the intervention began. Statistical testing showed no significant difference between EMIS and other patients at baseline in sex, number of repeat prescriptions, or SF-36 scores.

\section{Sample size}

Although there are no data on intra-cluster correlation coefficients for the UK-MAI, the authors' experience is that very few intra-practice correlation coefficients (IPCCs) exceed 0.1 and few exceed 0.05.19 The estimated power of RESPECT was based on an IPCC of 0.1 . To yield $80 \%$ power to detect differences in UK-MAI between intervention and control of 0.4 of a population standard deviation (regarded as a small to moderate effect size), with a significance level of $5 \%$, this requires an effective sample of 210 . As the mean cluster size in the RESPECT trial is about 10, an achieved sample of 400 is needed (210 multiplied by 1.9). Because losses to follow-up, including mortality and institutionalisation, were conservatively estimated at $40 \%$, the target sample was set at 700 . In the event, 760 were recruited, 209 (27.5\%) were lost, and thus, 551 were followed through pharmaceutical care (Figure 1).

\section{Analysis}

All analyses were by intention to treat. Where possible, participants lost to follow-up were included by using all their available data. However, 37 patients who died before the start of pharmaceutical care were excluded. Analysis was performed on the patient outcomes collected at the different time points. Each patient could have outcomes measured at five time points, so outcomes are nested within patients. In turn, each patient belongs to a practice and each practice to a PCT, so measurements are nested within patients within practices within PCTs. To account for this hierarchical structure, researchers 
tried to fit a mixed model that took into account variation at each level, as well as the correlations between repeated measures. The 'PROC Mixed' procedure was used in the Statistical Analysis System (SAS version 8) with a general prior covariance structure. The main analytical model (for the UK-MAI) included the intervention, PCT, participants' ages and numbers of repeat drugs (because the UK-MAI depends on that) as fixed effects, and time and the interaction between intervention and time as random effects. As the design was longitudinal, the aim was to study the effect of the intervention on the UK-MAI over time. Hence there are two key concepts in this model: the intervention shows the immediate effect of pharmaceutical care on the appropriateness of the patient's drugs (in the form of a step change; key in Figure 2); and the interaction between intervention and time shows how pharmaceutical care changes the slope of the appropriateness trajectory. The secondary analytical models (for SF-36 mental and physical component scores) were similar except that number of drugs was not needed as a covariate. The fit of all these statistical models was checked.

All serious adverse events, notably deaths and lifethreatening events were also investigated and the nature of these events and possible causes, such as participation in pharmaceutical care, was examined. When trial participants suffered a serious adverse event, their GP completed a structured form. Two clinical members of the research team reviewed these forms, together with all relevant information, especially the pharmaceutical care plans produced by pharmacists. Hospital admissions were also recorded during final data collection.

\section{RESULTS}

\section{Recruitment}

A total of 110 general practices from five PCTs were approached with information about the trial, of which 45 expressed a definite interest. From these 24 practices were selected to take part in the trial, using a random selection approach involving stratification according to PCT region and practice size. The study also recruited 62 community pharmacies across the five regions; then 760 patients were recruited into the trial from an original list of 3100 , who were identified as potentially suitable from practice records (Figure 1). The original sample size calculation was based on an IPCC estimate of 0.1 . Using a random intercept model and the UK-MAI score at recruitment, the actual IPCC was calculated to be 0.02 , indicating that the original calculation was appropriate.

Mean age of the patients recruited was 80 years (standard deviation $[S D]=4.1$ ), 57\% were female, and the mean number of repeat prescribed items was seven $(S D=2.2)$. Mean total UK-MAI score per patient at baseline was $23.6(S D=19.5)$ and the mean physical and mental components of the SF-36 were $33.0(\mathrm{SD}=10.4)$ and $47.8(\mathrm{SD}=12.2)$ respectively (Table 1 ).

\section{Pharmaceutical care}

Of the 673 participants who reached baseline, 563 (84\%) had their medication reviewed on at least one occasion and therefore received pharmaceutical care, with a mean number of 8.3 reviews conducted for each of these people. Both the proportion of people who actually began pharmaceutical care and the number of reviews completed varied considerably across different $\mathrm{PCT}$ regions, ranging from $55 \%$ to $88 \%$ and 4.1 to 11.1 respectively.

\section{Primary outcome}

Analysis showed that the design had underestimated the number of drugs prescribed to patients at the final time point used in the study. This discrepancy arose due to a programming error in the study's method of presenting extracted medication data electronically. For each of the earlier four time points, UK-MAI assessors were presented with data

\begin{tabular}{|c|c|c|c|c|c|c|}
\hline Characteristic & $\begin{array}{l}\text { PCT A } \\
n=95\end{array}$ & $\begin{array}{l}\text { РCT В } \\
n=88\end{array}$ & $\begin{array}{l}\text { РCT C } \\
n=192\end{array}$ & $\begin{array}{c}\text { PCT D } \\
n=286\end{array}$ & $\begin{array}{l}\text { РСТ Е } \\
n=99\end{array}$ & $\begin{array}{c}\text { Total } \\
n=760\end{array}$ \\
\hline Age in years, mean (SD) & $\begin{array}{c}79.9 \\
(3.95)\end{array}$ & $\begin{array}{c}80.5 \\
(4.11) \\
\end{array}$ & $\begin{array}{c}80.8 \\
(4.25) \\
\end{array}$ & $\begin{array}{r}80.4 \\
(4.09) \\
\end{array}$ & $\begin{array}{c}79.6 \\
(3.96) \\
\end{array}$ & $\begin{array}{c}80.4 \\
(4.11) \\
\end{array}$ \\
\hline \multicolumn{7}{|l|}{ Sex, $n(\%)$} \\
\hline Males & $\begin{array}{c}54 \\
(56.8)\end{array}$ & $\begin{array}{c}51 \\
(58.0)\end{array}$ & $\begin{array}{c}118 \\
(61.5)\end{array}$ & $\begin{array}{c}156 \\
(54.5)\end{array}$ & $\begin{array}{c}53 \\
(53.5)\end{array}$ & $\begin{array}{c}432 \\
(56.8)\end{array}$ \\
\hline Females & $\begin{array}{c}41 \\
(43.2)\end{array}$ & $\begin{array}{c}37 \\
(42.0) \\
\end{array}$ & $\begin{array}{c}74 \\
(38.5) \\
\end{array}$ & $\begin{array}{r}130 \\
(45.5) \\
\end{array}$ & $\begin{array}{c}46 \\
(46.5) \\
\end{array}$ & $\begin{array}{c}328 \\
(43.2) \\
\end{array}$ \\
\hline \multicolumn{7}{|c|}{ Total UK-MAI per participant $(0=$ best $)$} \\
\hline Valid $n$ & 80 & 74 & 108 & 212 & 85 & 559 \\
\hline Mean & 24.5 & 18.6 & 29.2 & 21.9 & 24.3 & 23.6 \\
\hline (SD) & $(19.4)$ & $(18.7)$ & $(22.4)$ & $(15.9)$ & $(23.1)$ & (19.5) \\
\hline \multicolumn{7}{|c|}{ SF-36 physical component score (lower = worse) } \\
\hline$n$ & 93 & 87 & 186 & 279 & 97 & 742 \\
\hline $\begin{array}{l}\text { Mean } \\
\text { (SD) }\end{array}$ & $\begin{array}{c}31.9 \\
(10.3)\end{array}$ & $\begin{array}{l}34.6 \\
(9.8)\end{array}$ & $\begin{array}{c}32.8 \\
(10.0)\end{array}$ & $\begin{array}{c}33.3 \\
(10.6)\end{array}$ & $\begin{array}{c}32.2 \\
(10.9)\end{array}$ & $\begin{array}{c}33.0 \\
(10.4)\end{array}$ \\
\hline \multicolumn{7}{|c|}{ SF-36 mental component score (lower $=$ worse) } \\
\hline$n$ & 93 & 87 & 186 & 279 & 97 & 742 \\
\hline $\begin{array}{l}\text { Mean } \\
\text { (SD) }\end{array}$ & $\begin{array}{c}45.2 \\
(13.2)\end{array}$ & $\begin{array}{c}49.3 \\
(13.2)\end{array}$ & $\begin{array}{c}48.7 \\
(11.5)\end{array}$ & $\begin{array}{c}48.5 \\
(12.1)\end{array}$ & $\begin{array}{c}45.5 \\
(11.7)\end{array}$ & $\begin{array}{c}47.8 \\
(12.2)\end{array}$ \\
\hline \multicolumn{7}{|c|}{ Number of items on repeat prescription } \\
\hline$n$ & 95 & 88 & 192 & 286 & 99 & 760 \\
\hline Mean & 6.96 & 7.72 & 7.18 & 7.36 & 7.23 & 7.29 \\
\hline (SD) & $(1.93)$ & $(2.89)$ & $(2.07)$ & $(2.25)$ & $(2.07)$ & (2.23) \\
\hline \multicolumn{7}{|l|}{ UK-MAI per scored drug } \\
\hline$n$ & 80 & 74 & 108 & 212 & 85 & 559 \\
\hline Mean & 3.17 & 2.29 & 3.84 & 2.94 & 3.07 & 3.08 \\
\hline (SD) & $(2.36)$ & (1.91) & (2.24) & (1.73) & $(2.36)$ & $(2.10)$ \\
\hline
\end{tabular}

UK-MAI = UK Medication Appropriateness Index. 


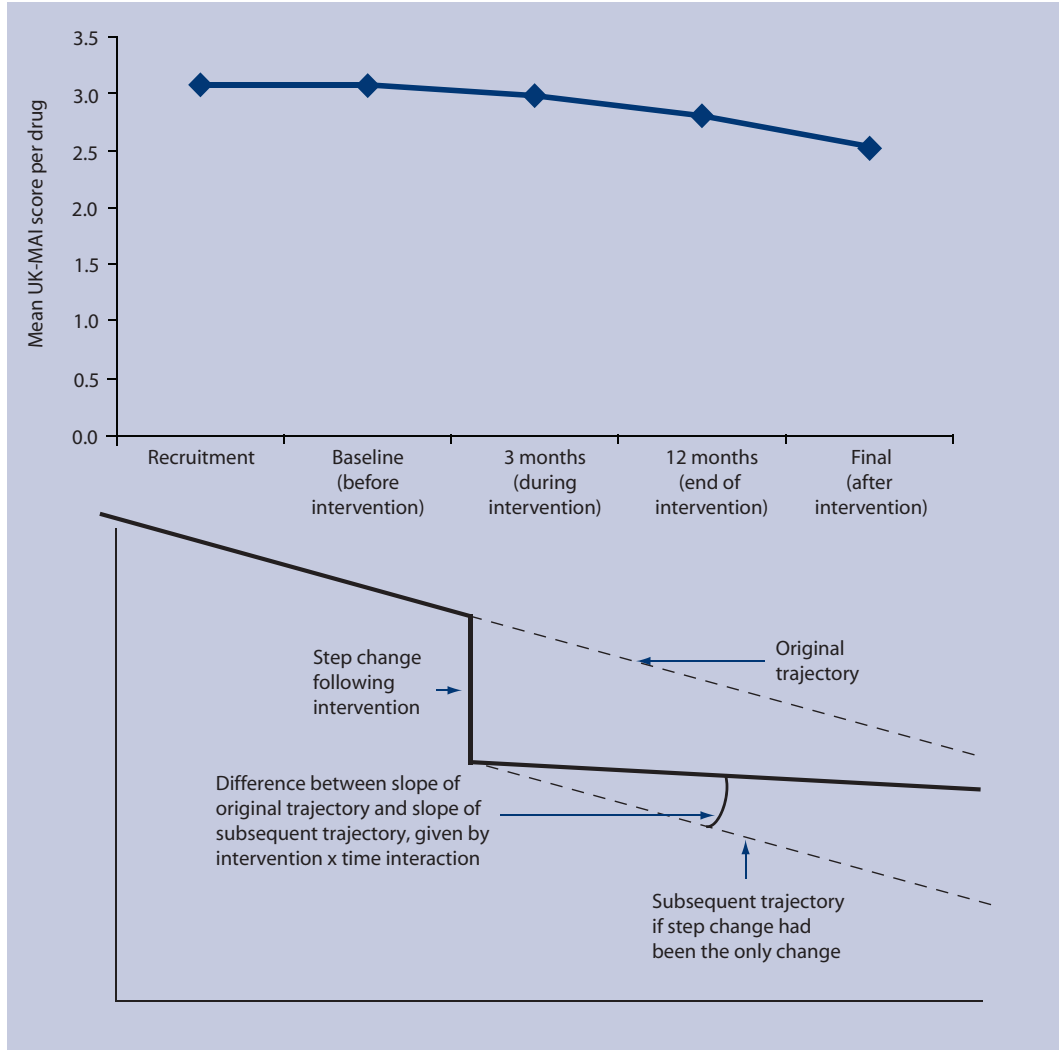

Figure 2. Top: mean UK Medication Appropriateness Index (UK-MAI) scores per scored drug over five time points. Refer to Appendix 3 for actual mean values. Bottom: key illustrating the changes expected according to the model used to analyse these data.

collected over a window of 2 months on either side of the time point, that is, 4 months of medication data. However, the final window comprised only 2 months of data before the fifth time point. Mean number of drugs shown on prescription at the final time point was 6.99 per participant $(S D=2.69)$, compared with 8.11 (SD = 3.16) over the four previous 4-month windows: a difference of 1.14 $(95 \%$ confidence interval $=1.01$ to 1.27 ).

As the number of drugs prescribed affects the UKMAI score, this also fell. This appeared to indicate that medication appropriateness had improved at the final follow-up time point. However, this was a spurious result, being directly attributable to the shorter data extraction period for the final time point rather than a true reduction in the UK-MAI. This problem was addressed by re-examining medication data and identifying 180 patients for whom there was no difference between 2 and 4 month periods for the drugs they were prescribed at the final time point (Appendix 3). Knowing that their scores for medication appropriateness would have been unaffected by this issue, all of their data were used for the UK-MAI analyses. For other patients, only the first four data points were included and set the fifth to missing. Fortunately, the way in which these data were missing was consistent with being missing at random, thus permitting the proposed mixed-model analysis.

It was not possible to fit three-level models (measurements within patients within general practices) because the mathematical models could not 'converge' on a feasible solution. Instead, twolevel models (measurements within patients) were fitted. When the fit of these models was checked, those with UK-MAI as a dependent variable produced skewed residuals. A better fitting model was achieved by transforming the UK-MAI by taking the square root. The resulting model showed no evidence to suggest that the medication appropriateness score had changed significantly over time. Neither time nor the intervention, nor the interaction between them, was significant. There was no evidence to suggest that the intervention had any impact on the MAl score. Figure 2 shows the mean UK-MAI values for patients at all time points and illustrates the step change the researchers were looking for in the analyses; Appendix 4 shows the transformed parameter estimates.

Given the problems with the fifth time point, the primary analysis was repeated using only the first four time points. This led to the same conclusions as the previous analyses. The analysis had failed to find any significant effect of the intervention on UK-MAI score.

\section{Secondary outcomes}

The SF-36 physical and mental scores both reduced over time, indicating a decline in both physical and mental health. There was a decline in the mental component scale $(P=0.039)$. However, there was no evidence in either model that pharmaceutical care altered the rate of decline because neither the intervention nor the time-intervention interaction was significant. Figure 3 shows the mean SF-36 values at each time point (see Appendix 3); Appendix 4 shows the parameter estimates for the regression models.

From the 161 notifications of serious adverse events, researchers investigated 55 sets of forms and pharmaceutical care plans where the serious adverse event was potentially attributable to the intervention. No evidence was found that pharmaceutical care had caused any of these serious adverse events, and therefore none were reported to the Trial Steering Committee in its role as Data Monitoring and Ethics Committee. Furthermore, statistical analysis yielded no evidence that pharmaceutical care had affected the number of reported hospital admissions or other episodes of secondary care, as shown in the lower section of Appendix 4.

\section{DISCUSSION}

\section{Summary of main findings}

Pharmaceutical care is a relatively new concept to 
UK primary care. Pharmacists seek to assess and modify prescribing through collaboration with GPs. In developing their pharmaceutical care plans, pharmacists consider the patients, their symptoms, their prescriptions, and how these can be improved. Although widely practised within secondary care in the UK by ward-based clinical pharmacists, pharmaceutical care has not been widespread within primary care. Nevertheless, a limited form of medication review was included in the 2005 Community Pharmacy Contract for community pharmacists. $^{20}$

RESPECT is the first randomised controlled trial to evaluate the provision of pharmaceutical care by community pharmacists in primary care in England. By studying more than 700 participants it showed that 12 months of pharmaceutical care delivered by community pharmacists to older people did not affect the appropriateness of 'repeat' medication as assessed by the newly developed UK-MAI. Furthermore, the intervention had no effect on physical or mental health, or on serious adverse events.

\section{Strengths and limitations of the study}

This trial studied ambulant older people on multiple repeat prescriptions: a group at high risk of medication problems, including poor compliance and adverse drug reactions, who in comparison to nursing home patients have greater control over their medicines. ${ }^{2}$ It covered five PCTs and adhered closely to its published design, a PCT-randomised multiple interrupted time series. This provided a robust approach to evaluating this topical intervention, because community pharmacy was expected to extend its role nationally over the period of the trial. ${ }^{9}$ RESPECT exceeded its recruitment targets, and kept attrition well below target.

Self-selection of general practices may have excluded those practices associated with poorer standards of prescribing, which could have affected the results of this study. Although the study design underestimated the number of drugs prescribed at the end of the study, researchers corrected for this by focusing on UK-MAI scores that were based on accurate and complete drug information.

\section{Comparison with existing literature}

Previous rigorous studies of pharmacists' interventions had shown little or no benefit to patients in appropriateness of medication, drug knowledge, rates of hospital admissions, or quality of life..$^{21-26}$ These studies, together with the findings of a recent systematic review, ${ }^{27}$ provide no evidence to support the roll-out in primary care of pharmacist-led medication review in general, or pharmaceutical care in particular. RESPECT extended the scope of these evaluations to assess national proposals to extend the roles of community pharmacists. ${ }^{6,7}$ It identified no benefit to patients from pharmaceutical care. ${ }^{5}$ However, pharmaceutical care did not increase hospital admissions, as was found in one previous study. ${ }^{23}$

\section{Implications for future research and clinical practice}

The lack of positive evidence from RESPECT stems from the researchers' experience that pharmaceutical care is difficult to implement fully in the community. Implementation depends on the relationship between pharmacist and GP. However, community pharmacists often do not know the GP who receives their care plan. Several pharmacists reported difficulties in trying to organise meetings with patients and also GPs in order to prepare and discuss care plans. This led to delays and missed reviews. Administrative problems sometimes meant that GPs were not notified when a care plan requiring their attention was delivered. Pharmacists were also typically unable to gather full and detailed clinical histories, which led to frustration on the part of some GPs when their prescribing was questioned.

Figure 3. Mean Short Form-36 Health Survey (SF-36) physical component scores (PCS: top) and mental component scores (MCS: bottom) over five time points.

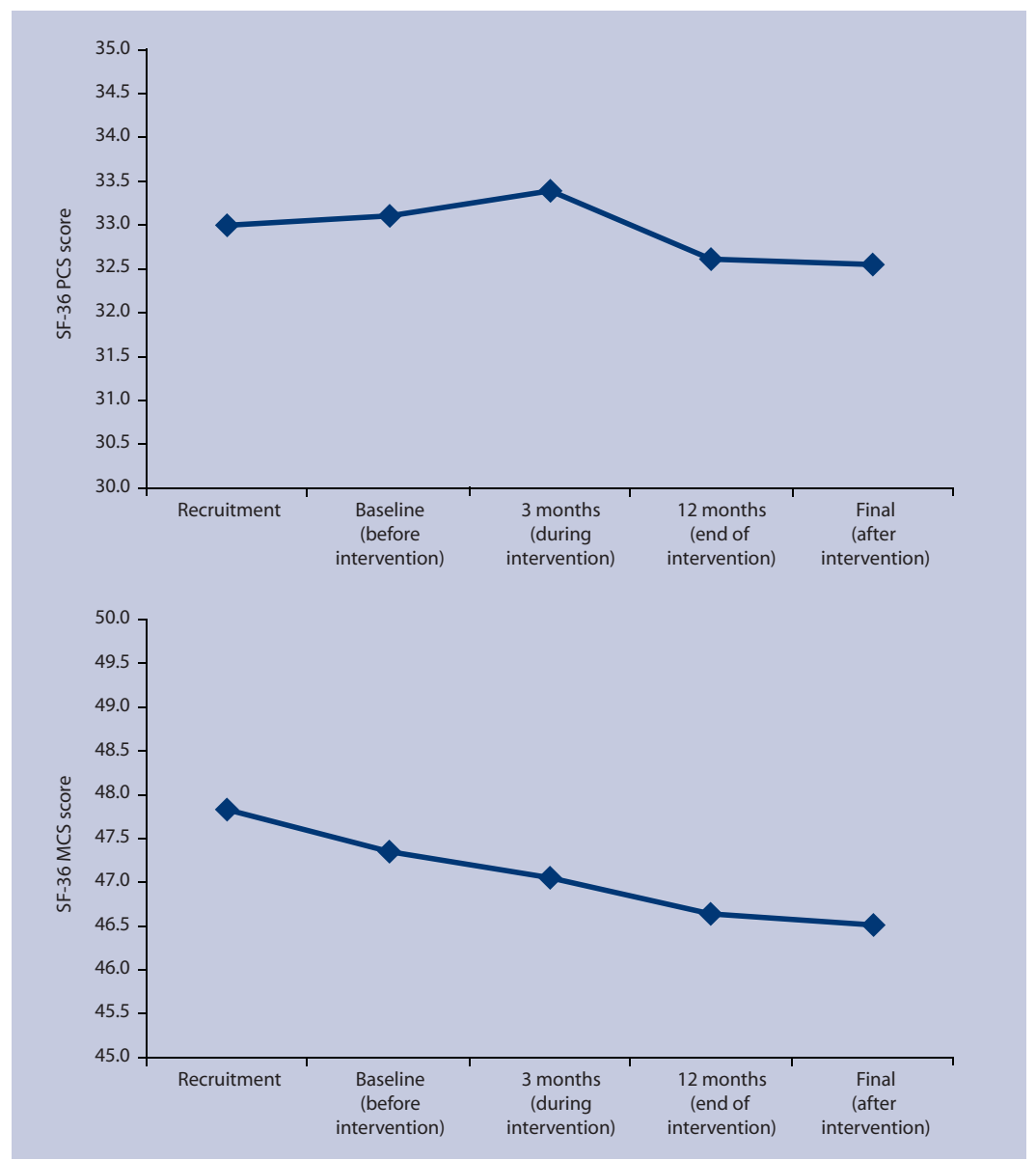


Although RESPECT sought to address issues such as these by providing joint training events for GPs and pharmacists, greater collaboration may be needed. In particular, without access to patients' medical records, community pharmacists may have difficulty in following the GPs' clinical prescribing decisions, resulting in uninformed suggestions in pharmaceutical care plans.

Providing pharmaceutical support for GPs and medication reviews within general practices, ${ }^{28}$ involving other GPs and clinicians in the review process as opposed to pharmacists, or limiting pharmaceutical care to specific groups of older people, may each be more effective and worthy of further research. Nevertheless, it is important to consider the cost-effectiveness of pharmaceutical care as employed in the present trial before drawing firm conclusions. ${ }^{10}$

\section{Funding body}

Research costs: Medical Research Council (grant reference G0001150). Excess treatment costs: Eastern Hull Primary Care Trust; East Yorkshire Primary Care Trust; Selby \& York Primary Care Trust; West Hull Primary Care Trust; and Yorkshire Wolds \& Coast Primary Care Trust

\section{Ethic approval}

Hull \& East Riding Research Ethics Committee (reference number 06/01/107). York Research Ethics Committee (reference number 02/05/005)

\section{Competing interests}

The authors have stated that there are none

\section{Acknowledgments}

With thanks to: Hilary Edmondson, Karen Goodyear and Andrew Hersom for support with the grant application; the MRC and PCTs for funding; all the health professionals and patients who participated in the research; Professor Lewis Ritchie (University of Aberdeen), Professor Alain Li Wan Po (Aston University), and $\mathrm{Dr}$ Susan Ambler (Royal Pharmaceutical Society of Great Britain) for serving on the trial steering committee; Professors David Torgerson (Director of York Trials Unit, University of York), Mark Sculpher (Director of Centre for Health Economics, University of York), and Chris Bojke (Centre for Health Economics, University of York) for academic support; all who contributed to developing the UK Medication Appropriateness Index; 15 undergraduate pharmacy students from Bradford School of Pharmacy who assisted with data collection; and Elizabeth Jones (University of Hull), Bee Lian Sim (University of London), and Valerie Wadsworth (University of York) for secretarial support. Ian Chi Kei Wong's post was funded by a Department of Health National Public Health Career Scientist Award at the time of the study.

\section{Authors' contributions}

Stewart Richmond was trial manager, responsible for overall management and quality assurance. He contributed to the design, implementation, and management of the trial, developing procedures and data collection instruments, the design, implementation, and management of the recruitment and data collection plan, analysing and interpreting data, and writing this paper.

Peter Campion was grantholder and principal investigator responsible for recruitment and training in primary care. $\mathrm{He}$ contributed to the original grant application, and the design, implementation and management of the trial.

Henry Chrystyn was academic pharmacy adviser. He contributed to the design, implementation and management of both the introduction of pharmaceutical care and the trial. Simon Coulton was trial data manager, responsible for database design and management. He contributed to the design and implementation of the trial, and developing questionnaires and data collection instruments.

Ben Cross was assistant trial data manager. He contributed to database design and management.

Amanda Farrin was trial statistician until November 2004 and statistical adviser thereafter. She contributed to the design and implementation of the trial, developing data collection procedures and instruments, the statistical analysis plan, and the interpretation of results.

Andrea Hilton was trial pharmacist, responsible for implementing and managing the introduction of, and training for, pharmaceutical care. She contributed to the design, implementation, and management of the trial, the anglicisation of the UK-MAI, developing and implementing procedures and data collection instruments, and writing this paper.

Graham Hill was pharmacy practice adviser. He contributed to the design, implementation, and management of pharmaceutical care.

Jeremy Miles was trial psychometrician responsible for the validity and reliability of questionnaires and data collection instruments. He contributed to the design and implementation of the trial, and the analysis and interpretation of data.

Veronica Morton was trial statistician from December 2004, responsible for developing and implementing the statistical analysis plan, and validating data statistically. She contributed to implementing and managing the trial, and managing, analysing, and interpreting data.

Zoë Philips was trial economist, responsible for designing and implementing the economic evaluation plan. She contributed to designing, implementing, and managing the trial, developing procedures and data collection instruments, and managing, analysing, and interpreting data.

lan Russell was grantholder and principal investigator responsible for trial methods. He contributed to the original grant application, the design and implementation of the trial, the economic protocol, interpreting data, and writing this paper. lan Wong was grantholder and chief investigator responsible for the pharmacy component of the trial. He contributed to the original grant application, and the design, implementation and management of the trial. He guarantees the clinical content of this paper.

All authors commented on successive drafts of this paper, and can defend its content.

\section{Discuss this article}

Contribute and read comments about this article on the Discussion Forum: http://www.rcgp.org.uk/bjgp-discuss

\section{REFERENCES}

1. Department of Health. National service framework for older people. London: Department of Health, 2001. http://www.dh.gov.uk/en/publicationsandstatistics/publications/publi cationspolicyandguidance/DH_4003066 (accessed 6 Nov 2009).

2. Aparasu RR, Fliginger SE. Inappropriate medication prescribing for the elderly by office-based physicians. Ann Pharmacother 1997; 31(7-8): 823-829.

3. Pirmohamed M, James S, Meakin S, et al. Adverse drug reactions as cause of admission to hospital: prospective analysis of 18820 patients. BMJ 2004; 329(7456): 15-19.

4. Royal College of Physicians. Medication for older people. 2nd edn. London: Royal College of Physicians, 1997.

5. Hepler CD, Strand LM. Opportunities and responsibilities in pharmaceutical care. Am J Hosp Pharm 1990; 47(3): 533-543.

6. Royal Pharmaceutical Society of Great Britain. Report on June council meeting (mimeo). London: RPSGB, 1998.

7. United Kingdom Clinical Pharmacy Association. Statement on pharmaceutical care. London: UKCPA, 2000. http://www.ukcpa.org/category2.php?id=2 (accessed 2 Dec 2009).

8. Crealey GE, Sturgess IK, McElnay JC, et al. Pharmaceutical care programmes for the elderly: economic issues. Pharmacoeconomics 2003; 21(7): 455-465.

9. Wong ICK, Campion PD, Coulton S, et al. on behalf of RESPECT team. Pharmaceutical care for elderly patients shared between community pharmacists and general practitioners: a randomised evaluation. BMC Health Serv Res 2004; 4(1): 11.

10. RESPECT Trial Team. Cost-effectiveness of shared pharmaceutical 


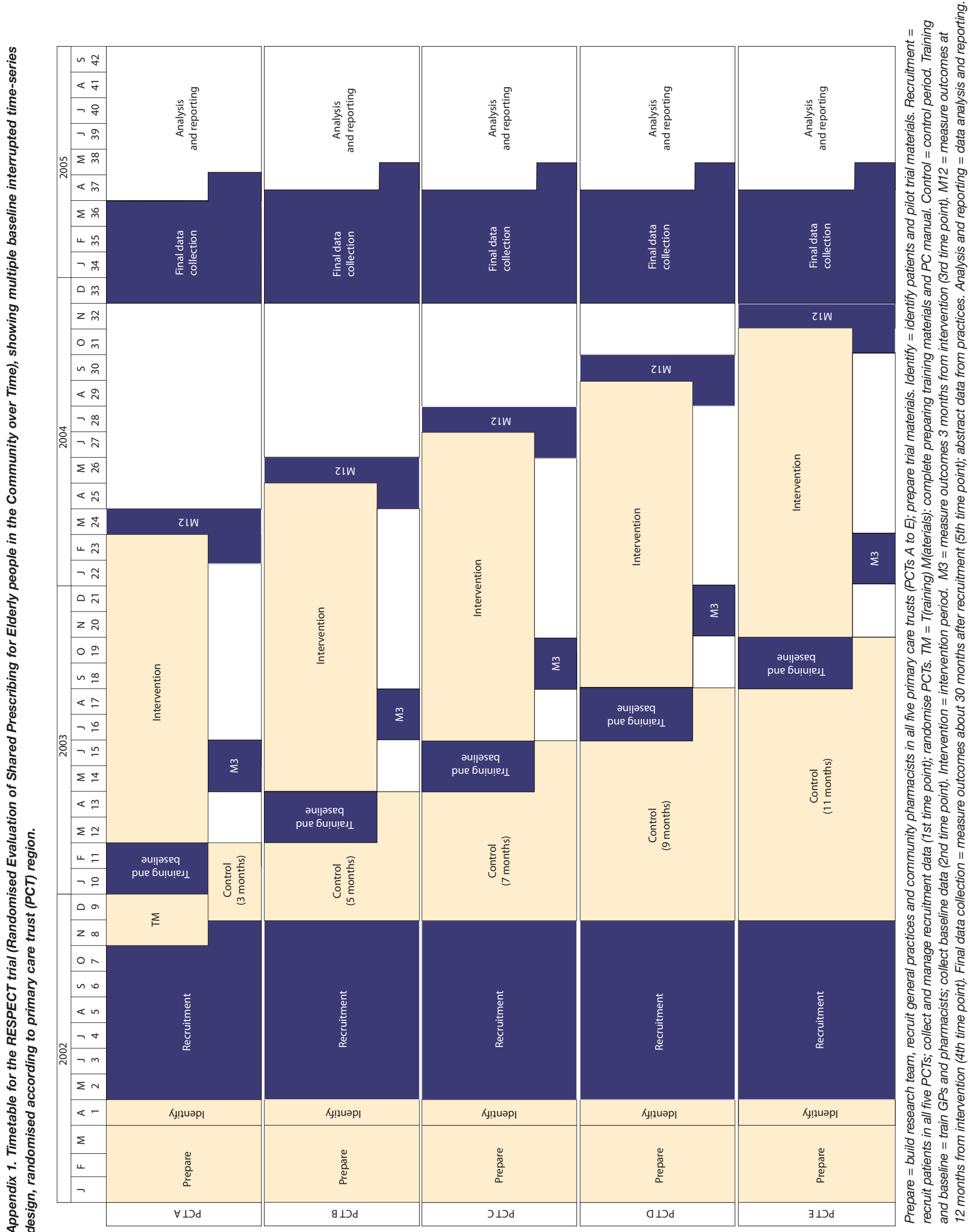


care for older patients: RESPECT trial findings. Br J Gen Pract 2010; DOI: $10.3399 /$ bjgp09X482312.

11. Medical Research Council. Cluster randomised trials: methodological considerations. London: MRC, 2002.

12. Cook TD, Campbell DT. Quasi-experimentation: design and analysi issues for field settings. Boston, Massachusetts: Houghton Mifflin, 1979.

13. Hodkinson HM. Evaluation of a mental test score for assessment of mental impairment in the elderly. Age Ageing 1972; 1(4): 233-238.

14. Hanlon JT, Schmader KE, Samsa GP, et al. A method for assessing drug therapy appropriateness. J Clin Epidemiol 1992; 45(10): 1045-1051.

15. Hanlon JT, Weinberger M, Samsa GP, et al. A randomized, controlled trial of a clinical pharmacist intervention to improve inappropriate prescribing in elderly outpatients with polypharmacy. Am J Med 1996; 100(4): 428-437.

16. Hanlon JT, Schmader KE, Koronkowski MJ, et al. Adverse drug events in high risk older outpatients. J Am Geriatr Soc 1997; 45(8): 945-948.

17. Ware JE, Sherbourne CD. The MOS 36-item short-form health survey (SF-36): I. conceptual framework and item selection. Med Care 1992; 30(6): 473-483.

18. EuroQol Group. EuroQol: a new facility for the measurement of health-related quality of life. Health Policy 1990; 16(3): 199-208.

19. North of England Study of Standards \& Performance in General Practice. Medical audit in practice: effects on doctors' clinical behaviour for common childhood conditions. BMJ 1992; 304(6840): 1480-1484.

20. Pharmaceutical Services Negotiating Committee. The New Community Pharmacy Contractual Framework: how a collaborative approach will benefit patients, GPs and PCTs. Aylesbury: PSNC, 2006.
http://www.psnc.org.uk/data/files/PharmacyContract/Information_f or_GPs/messages_for_gps_september_2006.pdf (accessed $23 \mathrm{Nov}$ 2009)

21. Zermansky AG, Petty DR, Raynor DK, et al. Randomised controlled trial of clinical medication review by a pharmacist of elderly patients receiving repeat prescriptions in general practice. BMJ 2001; 323(7325): 1340-1343.

22. Sturgess IK, McElnay JC, Hughes CM, et al. Community pharmacy based provision of pharmaceutical care to older patients. Pharm World Sci 2003; 25(5): 218-226.

23. Holland R, Lenaghan E, Harvey I, et al. Does home based medication review keep older people out of hospital? The HOMER randomised controlled trial. BMJ 2005; 330(7486): 293

24. Krska J, Cromarty JA, Arris F, et al. Pharmacist-led medication review in patients over 65: a randomized, controlled trial in primary care. Age Ageing 2001; 30(3): 205-211.

25. Community Pharmacy Medicines Management Project Evaluation Team. The MEDMAN study: a randomized controlled trial of community pharmacy-led medicines management for patients with coronary heart disease. Fam Pract 2007; 24(2): 189-200.

26. Denneboom W, Dautzenberg MG, Grol R, et al. Treatment reviews of older people on polypharmacy in primary care: cluster controlled trial comparing two approaches. Br J Gen Pract 2007; 57(542): 723-731.

27. Holland R, Desborough J, Goodyer L, et al. Does pharmacist-led medication review help to reduce hospital admissions and deaths in older people? A systematic review and meta-analysis. $\mathrm{Br} \mathrm{J} \mathrm{Clin}$ Pharmacol 2008; 65(3): 303-316.

28. Lowe CJ, Raynor DK, Purvis J, et al. Effects of a medicine review and education programme for older people in general practice. $\mathrm{Br} \mathrm{J} \mathrm{Clin}$ Pharmacol 2000; 50(2): 172-175.

\section{Appendix 2. Inclusion and exclusion criteria.}

Patients were eligible if:

they were $\geq 75$ years of age,

they were taking five or more 'repeat' drugs (excluding any taken 'when required'),

they were living at home,

- they were well orientated in time and place (scoring $\geq 7$ on the Abbreviated Mental Test ${ }^{13}$ ),

their GP gave consent,

their community pharmacist was taking part in the Randomised Evaluation of Shared Prescribing for Elderly people in the Community over Time (RESPECT) trial, and

they were able to provide written consent.

\section{Patients were not eligible if:}

they were living in a residential or nursing home,

they had impaired memory (scoring $\leq 6$ on the Abbreviated Mental Test ${ }^{13}$ ),

- their GP and community pharmacist were not in the same PCT, or

they had taken part in a local feasibility study. 
Appendix 3. Summary of data for each of the time points (as shown in Figures 2 and 3).

\begin{tabular}{|c|c|c|c|c|c|c|c|c|c|c|c|c|c|c|c|}
\hline \multirow[b]{2}{*}{ Average } & \multicolumn{3}{|c|}{ Recruitment } & \multicolumn{3}{|c|}{$\begin{array}{c}\text { Baseline } \\
\text { (before intervention) }\end{array}$} & \multicolumn{3}{|c|}{$\begin{array}{l}3 \text { months } \\
\text { (during intervention) }\end{array}$} & \multicolumn{3}{|c|}{$\begin{array}{l}12 \text { months } \\
\text { (end of intervention) }\end{array}$} & \multicolumn{3}{|c|}{$\begin{array}{c}\text { Final } \\
\text { (after intervention) }\end{array}$} \\
\hline & $n$ & Mean & SE & $n$ & Mean & SE & $n$ & Mean & SE & $n$ & Mean & SE & $n$ & Mean & SE \\
\hline UK-MAI & 559 & 3.08 & 0.09 & 529 & 3.07 & 0.09 & 526 & 2.99 & 0.09 & 510 & 2.81 & 0.08 & 180 & 2.54 & 0.13 \\
\hline SF-36 mental component score & 742 & 47.8 & 0.45 & 642 & 47.3 & 0.48 & 582 & 47.05 & 0.50 & 520 & 46.65 & 0.54 & 527 & 46.51 & 0.53 \\
\hline SF-36 physical component score & 742 & 33.0 & 0.38 & 642 & 33.1 & 0.40 & 582 & 33.40 & 0.43 & 520 & 32.60 & 0.44 & 527 & 32.56 & 0.44 \\
\hline
\end{tabular}

UK-MAI = UK Medication Appropriateness Index. SF-36 = Short Form-36 Health Survey. SE = standard error.

\section{Appendix 4. Parameter estimates from analyses.}

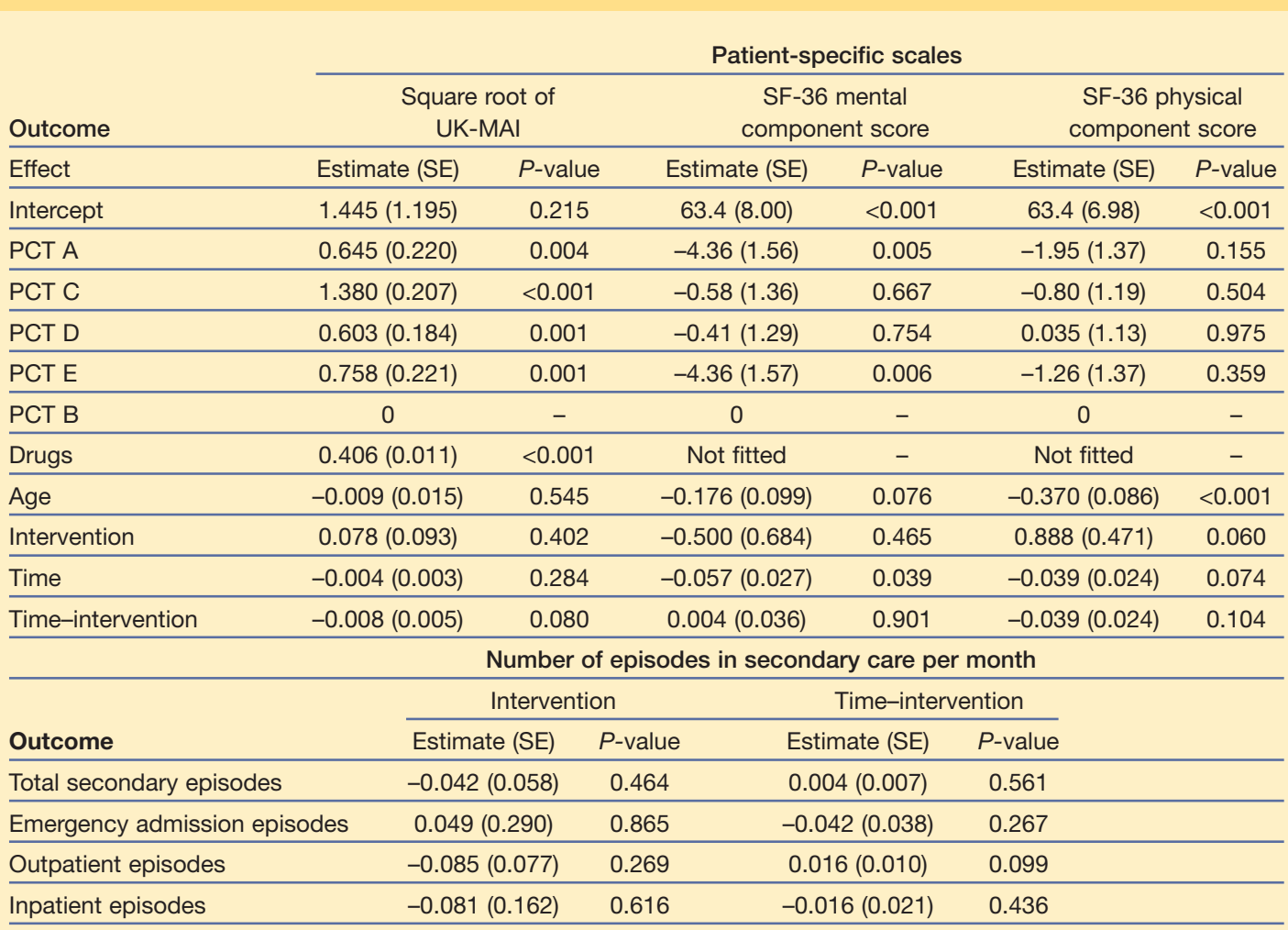

As dependent variables in the lower part of the table counted the number of episodes per month, results for Poisson regression models are displayed. The study also estimated more complex negative binomial models to account for an excess of zeros, but this hardly changed parameter estimates or improved the fit of the model. Additional covariates (not shown) were: sex, age,

number of repeat prescriptions, and the number of months since baseline and the square of this variable.

UK-MAI = UK Medication Appropriateness Index. SF-36 = Short Form-36 Health Survey. SE = standard error. 